\title{
CEGOS CRUZANDO A PONTE: TRAVESSIAS DA PESQUISA ACADÉMICA
}

\section{BLIND CROSSING THE BRIDGE: ACADEMIC RESEARCH CROSSINGS}

Clarissa Santos Silva 


\section{Resumo}

$O$ presente artigo discute os percursos da pesquisa acadêmica reconhecendo-os como processos de travessias. Através da representação gráfica de um sumiê de Hakuin Ekaku - Dois homens cegos cruzando uma ponte de tronco traçam-se paralelos entre as travessias da pesquisa e o cruzar de pontes dos homens ilustrados por Hakuin Ekaku: as incertezas, desafios, solidões, suportes e conquistas vivenciados no caminho do desenvolvimento evolutivo; nos cruzamentos do não-saber ao conhecimento. Apresenta-se, ainda, o olhar acerca de duas dissertações de mestrado, uma concluída e outra em andamento, como forma de reconhecer algumas dessas inquietações e experiências que movem o ser pesquisador.

Palavras-chave: Pesquisa. Dissertação. Travessias. Hakuin Ekaku.

\section{Abstract}

This article discusses the paths of academic research recognizing them as crossings processes. Through the graphical representation of a work by Hakuin Ekaku - Two blind men crossing a log bridge - parallels are traced between the crossings of research and the crossing of the men illustrated by Hakuin Ekaku: the uncertainties, challenges, solitudes, support and achievements experienced on the path of evolutionary development; the crossings of not- knowing to the knowledge. It presents also the analysis on two master's theses, a completed one and another in progress, as a way to recognize some of these concerns and experiences that move being a researcher

Keywords: Research. Master's thesis. Crossings. Hakuin Ekaku.

ISSN: 2175-2346

\footnotetext{
- Clarissa Santos Silva

Mestranda do Programa de Pós-graduação em Artes Visuais da UDESC Universidade do Estado de Santa Catarina. Membro do Grupo de Pesquisa Educação, Artes e Inclusão CNPq/UDESC e do Observatório da Formação de Professores no âmbito do Ensino de Arte: estudos comparados entre Brasil e Argentina - (OFPEA/BRARG), Graduada em Arte e Mídia, pela Universidade Federal de Campina Grande.

clarissabog@gmail.com
} 
Abordar a pesquisa acadêmica leva, primordialmente, a pensar sobre articulações teóricas, investigações de problemas e demandas, bem como, na ultrapassagem de espaços e caminhos estabelecidos na área estudada. É a fundante ideia da pesquisa como desbravamento científico. No entanto, para além de um desbravar acadêmico, a pesquisa pode ser compreendida como percurso e reconhecimento da nossa humanidade: nossos desejos e inquietações, nossas metodologias e ideologias, nossos afetos e linguagem, está tudo ali, posto em sentença; palavreado letra a letra, frase a frase. Disse Batista de Lima:

Toda palavra é uma claridade pousada sobre um enigma. Escrever é lutar com palavras. Fazer delas lanternas para as escuridões e ao mesmo tempo criar enigmas novos para os que nos sucederem, desvendarem-nos como treinamento para a criação de novos mistérios ${ }^{1}$.

Estamos ali, (ex)postos em nossas pesquisas, administrando encontros, articulando riscos e equilibrando seus delineamentos, dialogando com a incerteza. Somos construtores de abrigos, organizadores de apartamento, somos viajantes, cozinheiros e, acima de tudo, somos apaixonados. Estamos na pesquisa como aqueles que estão na experiência amorosa: investindo afetos e arriscando trajetos ${ }^{2}$. A pesquisa é um percurso, uma travessia. Estamos nela como cegos cruzando a ponte. Uma ponte vacilante, troncada, escorregadia.

O mestre e artista zen Hakuin Ekaku3 (1685-1768) revisitou pelo menos oito vezes a imagem de homens cegos que cruzam uma ponte de tronco. As linhas do sumi-ê são finas, delicadas, precisas. A mensagem, por sua vez, é profunda e densa. Ali está representada a travessia da iluminação, do autoconhecimento; o percurso árduo, incerto e repleto de temores, que deverá ser percorrido por aqueles que buscam mais sabedoria; aqueles que desejam atravessar as pontes do não-saber ao conhecimento.

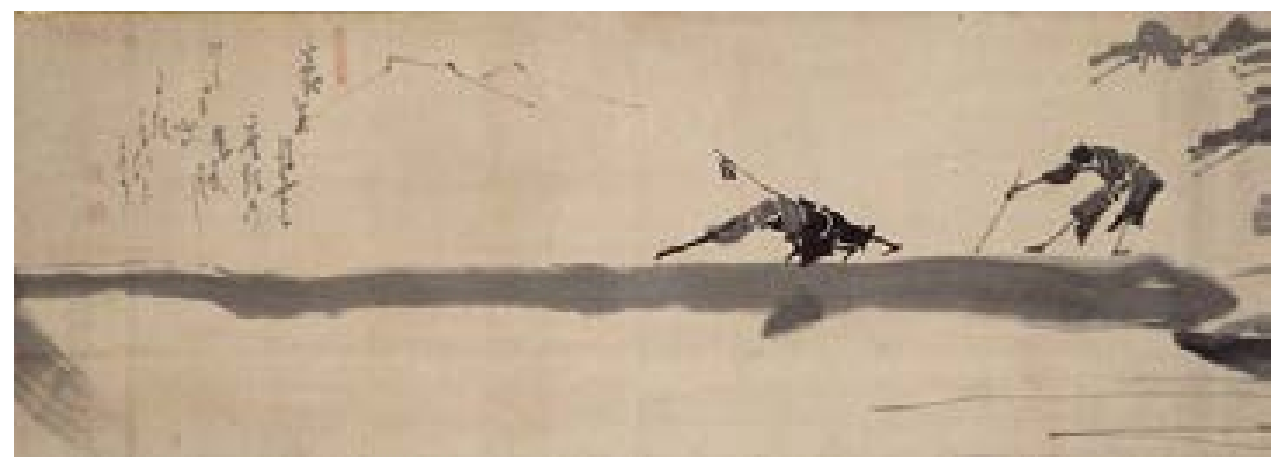

Figura 1 - Dois homens cegos cruzando uma ponte de tronco (Two blind men crossing a log bridge), Hakuin Ekaku. Tinta sobre papel de arroz. 28 x $83.8 \mathrm{~cm}$. The Manyo'an Collection, Gitter-Yelen Foundation. New Orleans, USA. Fonte: http://www.manyoancollection.org/

Não somos nós - pesquisadores - estes homens de Hakuin Ekaku? Um tateia o tronco agachado, buscando firmeza para uma travessia segura; vai sentindo a ponte como quem busca suas texturas, formas, sons; sua passagem é tátil e procura segu-

\footnotetext{
1 BATISTA DE LIMA, J. A arte de escrever. Publicações da Academia Cearense de Letras, 2009. p. 57-66. Disponível em: < http://www.academiacearensedeletras.org.br/publicacoes.php>. Acesso em: 16 de abr. 2016.

2 Tais concepções da pesquisa foram abordadas na disciplina Seminário de Pesquisa I, do PPGAV-UDESC, ministrada em seu primeiro módulo pela Profa. Dra. Rosangela Miranda Cherem. Este artigo é fruto das abordagens e reflexões suscitadas nesta disciplina

3 ADDISS, S.; LOORI, J. D. The Zen Art Book: The art of enlightenment. Boston, MA: Shambala 2007.
} 
rança para um percurso visivelmente perigoso e trêmulo. O outro apoia-se com a ajuda de um cajado ou galho, algo que estende suas possibilidades, lhe dá uma sustentação; é um equilibrista: de seus desejos, condições e razoabilidades.

Mas, o que nos move para a travessia? Que potência mobilizadora nos arremete para que queiramos dialogar com as incertezas e periculosidades desse cruzar de pontes? O que nos motiva a buscar esse crescimento de jornada? No pesquisador, há uma espécie de inquietação latente. Um movimento interno, pavio incendiário da curiosidade e desejo de descoberta, que faz surgir questões, que direciona intenções, que atiça o olhar e o pensamento para um objeto e objetivo. O pesquisador é essencialmente um ser inquieto. Essa excitação que move é fundamental para o ser que pesquisa, pois é esse fluxo que o impulsiona a querer atravessar a ponte do ponto do desconhecimento para um ponto de compreensão plausível.

A produção intelectual é ardilosa, por ser flutuante e escorregadia. Ela oscila e tem caprichos. O que chamamos de inspiração é a capacidade de reter e ampliar, com um toque próprio e único, um flash ou insight, uma coisinha de nada que atravessa o nosso pensamento e pode fugir. Porém, boa parte dessa inspiração é fruto da nossa capacidade de concentração, de disciplina, de esforço mental e até de teimosia. ${ }^{4}$

Há nesse trajeto múltiplos desafios. Um deles é transformar a inquietação em linguagem, em produção comunicativa. Escrever. Tecer um diálogo oportuno entre suas evidências, documentos, objeto, teoria, afetos explicativos e plausibilidades ${ }^{5}$. Produzir um texto é imergir nessas "pirações": "[...] consideram que a inspiração é uma 'piração' que não está apenas em ins/piração, mas está também em cons/piração, trans/piração, as/piração e outras ações de 'pirar'"'6. Quando pensamos e debatemos os percursos e abordagens de dissertações e teses, vemos quão proeminente são as trans/pirações e as/pirações no universo da pesquisa acadêmica.

Um exercício válido, portanto, é olhar para as pesquisas considerando os seguintes vieses: como o assunto se torna objeto de pesquisa? Qual recorte metodológico e teórico foi adotado? Como é feita a trama entre a documentação/evidencia empírica e as plausibilidades e afetos explicativos?7 Em suma, como o autor realizou a tessitura construtiva de suas "pirações"? O que o inquietou para cruzar tal ponte? De modo geral, a primeira pergunta revela de forma acentuada as inquietações do sujeito pesquisador. As demais questões são como o cajado do segundo homem cego de Ekaku: chegam para lhe dar sustentação na travessia.

Ao analisar a dissertação Lugar Publicação: artistas e revistas ${ }^{8}$, de Vanessa Schultz, a partir dos vieses supracitados, ficou evidenciado como a pesquisa acadêmica perpassa o fazer e o lugar de fala de seu autor. Nesta pesquisa, Vanessa Schultz desenvolve sua trama a partir da premissa inicial de olhar para as publicações impressas como lugar da obra de arte. Inicialmente, a autora introduz ao leitor uma

\footnotetext{
4 FREITAS, Maria Ester de. Viver a tese é preciso! In: BIANCHETTI, L.; MACHADO, A. M. N (Orgs). A bússola do escrever. 3.ed. São Paulo: Cortez, 2012.

5 Conceitos igualmente abordados e debatidos na disciplina citada anteriormente. Vide nota $\mathrm{n}^{0} 3$.

6 BATISTA DE LIMA, J. Op. cit.

7 Atividade proposta pela Profa. Dra. Rosangela Cherem durante a disciplina de Seminário de Pesquisa I - PPGAV/UDESC.

8 SCHULTZ, Vanessa. Lugar Publicação: artistas e revistas. 2008. 176p. Dissertação (Mestrado em Artes Visuais) - Centro de Artes, Universidade do Estado de Santa Catarina, Florianópolis. 2008. Disponível em: <http://ppgav.ceart.udesc.br/turma2_2006/dissertacoes/vanessa-schultz.pdf>
} 
base teórica e histórica acerca das potencialidades da mídia impressa: este lugar de reprodução e circulação, capaz de irromper debates acerca da consolidação de uma produção que abarca "[...] a opção pelo múltiplo; o aumento da acessibilidade; a varrida da aura; a liberação das habilidades manuais decorrente da troca das responsabilidades artísticas, que passaram a ser delegadas ao olhar e, depois, à mente."

A partir disso, apresenta a perspectiva da publicação como espaço expositivo, desvelando a possibilidade de "folhear uma exposição", uma exposição-publicação; um Lugar Publicação, que a autora investiga e explora como profícuo território de profusão artística. A dissertação, então, perpassa os espaços, movimentos, ações e pessoas de referência para este viés artístico e expositivo; a pesquisadora aborda diversos artistas e revistas que reconheceram e produziram nessa mesma perspectiva, construindo um repertório referencial, que alicerça a sua construção prática posterior. Desse modo, segue para a parte final, onde expõe seu processo artístico, a prática reflexiva concomitante à toda a imersão investigativa vivenciada. "Há nesta pesquisa um lugar no qual prática e pensamento se imbricam e trocam experiências entre si. Na mensuração de importância, não há distinção entre eles, ambos são estímulo, motivo e consequência um do outro."10

Com trabalhos concebidos para a publicação impressa como lugar primário para exposição das obras, Vanessa Schultz apresenta o desenvolvimento do projeto 4 intervenções e uma exposição coletiva. Empreendido através de seu trabalho como diretora de arte da revista Cartaz Cultura \& Arte e produzido em parceria com quatro artistas (Luana Veiga, Traplev, Jorge Menna Barreto e Paulo Bruscky), o projeto desvela-se como uma experimentação de percurso; uma vivência do seu cruzar de ponte.

Assim, percebemos que na inquietação da pesquisa há sempre estes traços de afetos. Uma pesquisa fala do seu autor tanto quanto poderia ser encontrado em sua biografia. Como corroborado por Maria Ester de Freitas: "No limite, nós somos o maior objeto da tese, pois enquanto sujeito dela vivemos o embate de forças internas e externas que nos ensina muito sobre nós mesmos" ${ }^{11}$. Neste caso, uma inquietação oriunda da problemática cotidiana de Vanessa Schultz - a saber, seu trabalho com publicações de revistas - gerou um movimento de pesquisa e realização de construção poética, pensando a publicação como espaço expositivo alternativo. É esse movimento interno que faz saltar o objeto de desejo do pesquisador: seu assunto. Bem como, encaminha suas questões, objetivos e direcionamentos.

Reconhecer nossa própria inquietude não é tarefa fácil, requer assumir nossas paixões, afetos, apegos. O nosso problema [de pesquisa] é a nossa ponte. Estamos sobre ela como seres desejantes, ávidos de perguntas, mas também trôpegos, tateando sua superfície e buscando completar a travessia.

$\mathrm{Na}$ dissertação que ora atravesso, como aluna do PPGAV-UDESC e junto ao Observatório da formação do professor no âmbito do ensino de arte: estudos comparados entre Brasil e Argentina (OFPEA/BRARG), o percurso tem sido trilhado com intuito de realizar um mapeamento e levantamento de dados através dos currículos dos cursos de licenciatura em Artes Visuais do Nordeste brasileiro, considerando as 
IES públicas com cursos presenciais e, neste processo, analisar a inserção das novas tecnologias na formação do professor em artes visuais. Entendendo que ainda nas licenciaturas é possível delinear novas abordagens e perspectivas para utilização pedagógica das novas tecnologias. Um delineamento que perpasse a necessidade de uma postura crítica, de pesquisa e reflexão do fazer docente, de modo a não reproduzir um discurso tecnicista na inserção tecnológica. Com essas premissas, lançome às perguntas: $O$ ensino das artes visuais pode colaborar com uma perspectiva reflexiva e humanizadora das tecnologias? Essas questões perpassam o currículo de formação deste professor? Qual o papel da arte nesse contexto?

Assim vejo a dissertação que empreendo: um percurso insólito que exploro, por vezes bambeando entre os trajetos a escolher, mas amparada pelo desejo das descobertas e pela jornada de crescimento. Nela entro munida apenas das perspectivas de onde parti: a educação, o ensino de arte, a reflexão para um contexto educacional mais correlato com as modificações sócio-comunicativas de seu tempo e a relação entre arte, educação e novas tecnologias. Durante o percurso tenho adquirido outras sustentações e direcionamentos: observar a formação do professor, a partir dos currículos, nas licenciaturas em artes visuais do nordeste brasileiro. Nordeste que é meu lugar de fala: meu espaço de nascença e vida, de construção e problematização.

Voltemos, então, a olhar para a obra de Hakuin Ekaku. Além do desejo pelo saber, pela elevação, que move, impulsiona e direciona a travessia, há outro aspecto que vale ser ressaltado: a aprendizagem solitária. Se olharmos para cada uma das figuras representadas, perceberemos como, apesar de estarem juntos no percurso, vivenciam individualmente seus posicionamentos e modos de enfrentar o desafio posto. Como explicita Marguerite Duras: "A solidão é aquilo sem o qual nada se faz. Aquilo sem o qual nada mais se olha."12

No contexto da pesquisa acadêmica, novamente, somos estes cegos que cruzam a ponte: "o que nos irmana é o processo"13. Estamos constantemente imersos em nossos próprios percursos de investigação, buscando os modos, métodos e teorias que poderão nos dar sustentação, angustiando-nos com prazos, produções, ambições e com a vida pessoal - que por vezes esquecemos possuir! "Nas cidades, nas vilas, em toda a parte, os escritores são pessoas sós. Foram-no sempre e em toda a parte." ${ }^{14}$ Estes e tantos outros processos solitários nos relacionam enquanto sujeitos pesquisadores, mesmo quando estamos cada qual - a seu modo -, desbravando nossas próprias veredas.

Compartilhamos solidões. Nos grupos de estudos, nos projetos de pesquisa, nas disciplinas e, especialmente, com nossos orientadores: a nossa solidão interessa, constrói, agrega. A solidão do outro toca e afeta nossa aprendizagem, também solitária. Apesar da pesquisa e sua escrita serem momentos de isolamento, há trocas fundamentais que ocorrem no entremeio desse processo. Somos seres deslocados: do percurso mercadológico usual, da reflexão comum, da produção artística ordinária e, por vezes, até da vivência social aceitável. Estamos deslocados de algumas esferas,

\footnotetext{
12 DURAS, Marguerite. Escrever. Trad. Rubens Figueiredo. Rio de Janeiro: Rocco, 1994. 
mas não estamos isolados.

Há que se valorar estas pessoas que dividem conosco este momento de travessia. Algumas estão lá, na mesma ponte que nós: assistindo aulas, indo a congressos, participando de debates, reuniões de grupo, orientações. Outras estão observando nossa trajetória deslocada e torcendo pelas descobertas e progressos que poderemos empreender. Assim, a aprendizagem e saber almejados nesse cruzar de pontes, deve perpassar também o reconhecimento de tudo e todos que carregamos como amuletos de equilíbrio, generosidade e crescimento. Posto que, a vivência do escrever significa também:

[...] valorizar as nossas conquistas e os apoios diversos que recebemos. [...] Quando estamos realmente abertos a um maior autoconhecimento, podemos aproveitar as lições recebidas, pois elas são muito reveladoras. Serão parciais, é verdade. Mas descobriremos que somos capazes de suportar conhecer as nossas limitações, a conviver com elas ou procurar reduzi-las. ${ }^{15}$

A pesquisa é este processo. De inquietações, solidão, descobertas; de travessia. Um percurso que requer de nós forças dolorosas: pensar e escrever. "Pensar dói"16. Escrever dói. As forças impreteríveis do corpo e da mente, que retrata Hakuin Ekaku, são o desafio diário daquele que pesquisa. "É preciso sermos mais fortes que nós para abordar a escrita, é preciso ser-se mais forte do que aquilo que se escreve"17.

Somos estes homens cegos cruzando uma ponte de tronco, desconhecida e escorregadia. Como o primeiro homem, vamos tateando a superfície, o território das teorias, das metodologias, do conceito de pesquisa; estamos com pés e mãos empenhados em reconhecer a ponte que queremos atravessar, buscamos a segurança de discurso, de embasamento, para firmemente seguirmos a construção de um saber. Como o segundo homem, temos suportes. Buscamos um equilíbrio entre nossa inquietação, as evidências, os afetos e plausibilidades da nossa pesquisa. Para tanto, apoiamo-nos em forças externas a nossa: seja ela advindo de nossas ideologias, crenças ou das pessoas-amuleto que reconhecemos pelo caminho.

Estamos nesse processo de travessia. Queremos cruzar esta ponte. Mas o que há do outro lado? O que nos espera na outra margem? Para onde a pesquisa nos leva? Olhemos o trajeto, lembremos os desafios, apreciemos as aprendizagens construídas. Pois, talvez, o que nos espreita na outra margem são os caminhos para novas pontes. São novas inquietações mobilizadoras, novas solidões compartilhadas, novos diálogos com a incerteza. "Foi, foi. Foi além. Foi completamente para a outra margem. Iluminação, quão maravilhosa!"18 E quantas travessias cabem numa vida?

\footnotetext{
$15 \quad$ FREITAS, Maria Ester de. Op. cit.

16 MAKOWIECKY, Sandra. Orientação: Porque Ele é Ele e Eu Sou Eu. In: CHEREM, R. M.; MAKOWIECKY, S. Os impreteríveis da pesquisa: considerações sobre o estado da pesquisa em/sobre arte no PPGAV/CEART/UDESC. Florianópolis: Coan, 2014.

17 DURAS, Marguerite. Escrever. Trad. Rubens Figueiredo. Rio de Janeiro: Rocco, 1994.

18 Sutra da Perfeição da Sabedoria ou Sutra do Coração, no budismo mahayana.
} 